\title{
11 \\ The search for an interim solution
}

\section{Brendan Tobin}

The role of scientist, scholar and lawyer should be to provide information and ideas, not to undertake the redefining of intellectual property rights. That should occur as the result of practice and experimentation by local communities. One thing is certain: the concept is not defined, and indeed, should not be defined in the immediate future (Posey 1994:240)

In September 1996, following a prolonged negotiation process lasting nearly three years, organisations representing the Aguaruna people of the Peruvian Amazon signed bioprospecting agreements with Washington University and the pharmaceutical arm of the Monsanto corporation, Searle and Company. The agreements provide for the collection and use of medicinal plants and associated traditional knowledge in the research and development of new pharmaceutical products.

The framework for negotiating the agreements was provided by the International Collaborative Biodiversity Group, ${ }^{1}$ which seeks to encourage the establishment of consortia of private sector, academic institutions and local actors for the research and development of new products through sustainable use of genetic resources. The agreements use a traditional contractual format, but in an innovative way and with the inclusion of novel terms and conditions. Their main aim is to secure indigenous peoples constant control over the collection and use of their knowledge, innovations and practices throughout the process of commercial research and development. Negotiation of the agreements involved finding a means to overcome some of the most controversial elements of the natural resource trade. 
Of particular importance in establishing these arrangements was the recognition of the reduced lead time which use of indigenous knowledge signifies for research and development activities. It was decided that the knowledge should be the subject of a specific know-how agreement, providing for an annual licence fee and advance royalties. The annual licence fee would be payable throughout research and development activities, and advance royalties would be paid in accordance with a schedule of milestones linked to clinical trials and new drug applications.

The agreements take the form of a contract for the collection of biological material and a separate know-how licence for use of indigenous knowledge. They were drafted in this way to prevent the acquisition of monopolistic rights, which might be used to limit the capacity of indigenous peoples to continue to use, share or market their biological resources, medicinal products or knowledge. It also secures recognition of the right of indigenous people to be compensated for use of their knowledge even where that knowledge has fallen into the public domain.

At the time these agreements were negotiated, there was no legislation in Peru governing access to genetic resources, or a regime to recognise and protect indigenous collective property interests. Given these constraints, the agreements are far from perfect. The process of their negotiation has, however, catalysed action by national authorities to draft and circulate legislation for the establishment of a sui generis regime for protection of collective property. This draft proposal will implement the provisions of Article 64 of Peru's new industrial property law, adopted in May 1996. This law gives the Ministry of Industry the power to adopt a special regime to protect the rights of indigenous peoples over their knowledge, including, if appropriate, the establishment of a register of knowledge interests.

This chapter is an attempt to draw some conclusions about potential mechanisms for protecting indigenous rights. It is based on experience gained while participating in the negotiation of the International Collaborative Biodiversity Group contracts, as legal adviser to the Aguarunas; and while serving as a member of the national working group for the development of legislation for a sui generis regime to protect indigenous collective property. The chapter examines a proposal, of which the author has previously been a sponsor, to use intellectual property regimes as a way of ensuring that prior informed consent becomes a condition for commercial use of traditional knowledge. 
The search for mechanisms to protect indigenous peoples' rights should begin from the position that any solution must come from indigenous peoples themselves. At present therefore, the most that can be achieved is the development of interim mechanisms that prevent the continued erosion of indigenous control over their collective property. Mechanisms of this kind should seek to provide indigenous peoples with the means to regulate use of their resources in a manner that ensures protection for present and future generations, and to secure equitable sharing of benefits derived from use. With that in mind, the proposals below may be seen as potential preliminary steps on the long road to equity.

\section{Issues in developing regimes for indigenous and collective property rights}

A technical discussion of how to protect rights over local and indigenous community knowledge must start from an understanding of what is to be protected, the nature of the material, its ownership, who would protect it, and against whom protection would be enforced. It must also consider the reasons why protection is being granted. Is it to prevent use, stimulate the market or promote innovation? If the means is to achieve the end, it is important to clarify these issues before developing the mechanism for protection. If, for example, indigenous communities primarily seek financial reward, then the approach adopted must be one which maximises returns. If, on the other hand, the main objective is to prevent unapproved use, or to impede use altogether, then a strict and demanding access regime might be what is sought.

\section{Elements of an access regime}

Analysis of the writings of commentators is helpful in identifying some fundamental issues that must be included in any regime to protect indigenous and local community collective property. The following features appear among the most widely identified objectives for an access regime

- ensure recognition of the collective nature of the knowledge, both within and among generations of indigenous peoples

- ensure that control of the use of knowledge remains firmly in the hands of indigenous peoples, even where such information is found within the so-called public domain 
- ensure that the exercise of rights by any community, group of communities, people or peoples does not infringe the rights of other communities or peoples to use, dispose of or otherwise control their resources

- avoid creating monopolistic rights over knowledge, and prevent the possibility of the acquisition of monopolistic rights over knowledge or the biological resources with which it is associated

- ensure equitable benefit sharing within and among communities

- assist in the revaluation of indigenous knowledge, promote traditional use and minimise adverse impacts on resources and cultures

- establish a presumption that the use of resources over which there exists knowledge, in particular regarding medicinal plants, implies use of that knowledge.

These objectives reflect the interests of the custodians of knowledge. In an ideal world the solution adopted would ensure complete compliance with these goals. But given practical realities, it is also necessary to consider a number of other questions. For instance, what capacity do national authorities have to establish a mechanism that can ensure realisation of these objectives? How can transaction costs be kept down? (If the system is too expensive benefits will end up being consumed by maintenance costs and will not reach communities.)

There are also important questions about dealing with rights on behalf of a collective. Can all communities and custodians of relevant knowledge be identified, and if so, is it feasible that they all be required to give consent for its use? What happens when these communities live in neighbouring countries? How can the use of material in the public domain be prevented? How can equitable sharing of benefits within communities be achieved without being paternalistic? How can sharing among communities, in particular those that do not have a history of cooperation, be achieved, again without resorting to paternalism? In what form should information be held in a register, and for what purpose? If the value of the knowledge is in keeping it confidential, how can the system ensure that potential users are aware of the identity of communities that must be consulted about the use of knowledge?

Coupled with these questions-about communities and their relationships with each other and government-are other questions about the role of private sector actors. With whom should they negotiate? Options include the whole community, custodians of particular knowledge or shamans, healers or leaders. How can legal certainty be secured so that the company is protected against future 
claims brought by other custodians of knowledge following development of an interesting product? Should warranties be sought from indigenous peoples regarding their right to enter into agreements? Can indigenous peoples be required to accept confidentiality obligations regarding research and development reports, and if so, will they be in a position to comply? To what extent are companies responsible for ensuring equity in distribution of benefits within and amongst communities? Should companies be obliged to pay royalties after patents expire? What happens when competitors are not paying royalties for information in the public domain? Is it fair that companies who entered into agreements should be prejudiced in competition with companies that are not paying royalties?

These questions identify only some of the significant issues to be taken into consideration in the search for an adequate and functional regime to protect knowledge rights. Although many articles have addressed the lack of adequate protection, and the inadequacies of existing intellectual property regimes, to date only a handful of proposals have been circulated which offer potential solutions to the problem.

\section{Sui generis systems}

The major proposals made so far, other than those which identify limited possibilities for use of existing intellectual property rights regimes, have focused primarily on development of sui generis protection and on the modification of reporting requirements under existing intellectual property rights application procedures. Although there appears to be a belief in some quarters that they are mutually exclusive, it is suggested here that an approach which incorporates both sui generis regimes and modification of existing intellectual property rights regimes may prove most appropriate. The former provides an avenue for recognition and protection of indigenous rights, and facilitates their exercise, and the latter serves to limit the possibilities for unapproved use of indigenous and local community resources in importing countries.

\section{History of development of alternative models}

The two major influences on the sui generis debate are the well known works of Gurdial Singh Nijar (1995) and Darryl Posey (1996a). Nijar's proposal for a collective property register, which has been circulating for a number of years, would entitle indigenous peoples to register their 
knowledge and utilise registration to control commercial use. Posey, on the other hand, focuses on an array of existing rights that together provide for recognition and protection of what he terms traditional resource rights. His model seeks, through recognition of a bundle of rights, to ensure the most comprehensive respect for, and protection of, indigenous and local community interests. However, Posey's proposal does not presume to provide the format for a system of protection. Rather, it identifies existing regimes each of which, when treated in unison, provide for recognition of and protection for indigenous rights.

While any regime should be developed with close attention to the bundle of rights Posey has identified, a mechanism must be found that can be applied as soon as possible to address the increasing uncompensated, unapproved use of indigenous knowledge, innovation and practices. For this purpose a more specific proposal regarding the format of legislation to recognise rights is required.

Nijar's proposal provides a basic format around which such a rights regime might be structured. The underlying principle that community rights can be recognised, registered and defended against unapproved use, while not impeding traditional transfers, is alluring. However, while $\mathrm{Nijar}$ proposes that these rights should be non-monopolistic, the right to impede commercial use does carry monopolistic connotations. Furthermore, while his proposal suggests a right that can be defended against abuse by third parties, he does not explain how local and indigenous communities could monitor international product development and intellectual property rights applications in order to control unapproved use of resources.

A third difficulty, and one that is common to the whole debate about indigenous rights, relates to the treatment of prior informed consent. This concept expresses the desire to ensure that all communities who share knowledge approve of its use. However, except where a number of communities share a commonality of purpose, this kind of approval would be all but impossible to secure. This is true even if it were possible to identify all the custodians of the relevant knowledge. A proposal that requires consent by all communities could effectively serve as a veto over the exercise of collective property rights, even by a majority of the communities' custodians of traditional knowledge. While this may be considered desirable in some cases (for example, to prevent cultural disintegration), it does not overcome the continuing problem of unapproved use, nor does it necessarily conform with the dynamic 
nature of indigenous societies and their right to adapt to development opportunities. Furthermore, it fails to respond to their need to find a means to protect their cultures in a globalised economy. The requirement for unanimous consent may even conflict with traditional decision making practices of many indigenous peoples, which might include weighted voting powers of elders and other important members of the society, or a form of majority decision making.

Despite the possible limitations of Nijar's proposal it does provide a good starting point for discussion of a mechanism for protection of indigenous interests. The tension between recognition of rights to prevent use and adoption of a non-monopolistic philosophy are not insurmountable. His proposal cannot, however, stand alone. It must be incorporated into a wider regime which includes international as well as national control mechanisms. If such an approach is taken, then freedom for indigenous and local communities to exchange information, in accordance with time honored non-monopolistic values, may be maintained.

In summary, a comprehensive collective rights regime would include both a sui generis national regime and a multilateral agreement for conditional use of knowledge, based on demonstrated prior informed consent for such use.

\section{Suggested elements of a sui generis regime}

The following proposal is a list of the principal elements that should be considered in the establishment of any collective rights regime. It is not intended to be exhaustive, and the principles set out below might be most appropriately considered as minimum conditions.

Inherent nature of the rights. The rights of indigenous and local communities over the product of their intellectual effort stem from their development of knowledge, innovations and practices and not from any act of government.

Rights may still exist in public domain material. Indigenous rights over knowledge, innovations and practices exist whether or not the information is considered to be within the public domain. The fact that information may be freely distributed by indigenous and local communities should not be seen as impeding their right to limit its use for commercial or scientific purposes, or for uses which are otherwise contrary to their spiritual or cultural morals. All prospective users must therefore be required to seek and obtain the prior informed consent of custodians of traditional knowledge. 
There is a commonly held misconception that material in the public domain cannot be the subject of intellectual property rights. However, within the United States, European Union and Japan there are examples of material that is protected in the public domain, including writings and designs. These experiences, which in the case of Japan and the European Union occurred within the last decade, are likely to be precedents for further efforts to protect public domain material. Similar protection of indigenous knowledge is therefore a possibility.

Cultural patrimony. The traditional knowledge rights of indigenous and local communities are collective in nature, both inter and intragenerationally, and should be recognised as cultural patrimony. ${ }^{2}$ These rights therefore cannot be alienated.

Distinguish indigenous rights from national sovereign rights. Where biological resources are considered national patrimony, there should be a clear distinction between the rights of the state over these resources and the collective property rights of indigenous peoples over their knowledge, innovations and practices. During the International Collaborative Biodiversity Group negotiations it was decided to adopt a contractual regime which clearly separated the benefits received for use of biological resources from the benefits received for use of knowledge. This was done to avoid the possibility of state intervention in benefit distribution, because of concerns that this would lead to an exhaustion of benefits in administrative overheads.

Intellectual property rights should not be monopolistic. Agreements for use must ensure that any intellectual property rights obtained by users cannot be utilised to prevent traditional use, or the sale, licensing or use of knowledge, innovations or practices, in any part of the world. They should also ensure that any rights (including patents) that are obtained on the basis of indigenous knowledge cannot be used to prevent the use, sale or licensing of those resources in any part of the world.

In many cases, agreements will not include all the custodians of particular knowledge. For example, on the Peruvian-Ecuadorian border five distinct indigenous tribes, all belonging to the Jivaro ethnic grouping, hold much of the same knowledge. It is important that an agreement such as the International Collaborative Biodiversity Group Peruvian agreement, which involved one of these tribes, the Aguarunas, should not prevent the other tribes from benefiting from their knowledge.

It is also important to ensure that compositional matter patents obtained by companies are not used to prevent the use or sale of 
medicinal plants containing the patented matter. Cases may arise where a company finds and patents compositional matter for a specific anticancer end. For example, it is very possible that if an indigenous people were to sell their medicinal plant within a protected market, with allusion to its anti-cancer properties, the sale could be challenged as a breach of the compositional matter patent.

Ownership of knowledge should be presumed from use of resources. The regime should establish a legal presumption that use of biological resources presumes ownership of knowledge about the properties of those resources. This presumption should operate where resources have historically been used by indigenous peoples or local communities for medicinal, biopesticide, phsycoactive or toxic purposes; or where the important characteristics of cultivated resources are confined to cultivars in clearly identifiable ecosystems. In such cases the rights to use the resource should be dependent on the user having a valid license to use the related knowledge.

Licences should be non-exclusive. While it is desirable that prior informed consent should be sought from all custodians of knowledge, innovations and practices, this may be impossible in many cases, at least for the moment. As such it is considered preferable that any contract or licences for the use of collective property should be of a non-exclusive nature. ${ }^{3}$

Review procedures. Any regime that recognises collective rights should establish administrative and judicial review procedures that allow custodians of knowledge, who are not party to an agreement, to challenge agreements for use of such knowledge in clearly defined circumstances. Challenges of this kind should be permitted on the basis that

- the contracting community or people are not legitimate custodians of the relevant knowledge

- benefit sharing is inadequate

- commercialisation of knowledge would undermine the culture or the people, or run counter to their spiritual beliefs

- commercialisation could lead to genetic erosion, loss of access for traditional uses or lead to undesirable incursions onto indigenous territories.

Equitable benefit sharing. The regime should establish mechanisms to secure equitable sharing of benefits among all custodians of collective property, whether or not they are parties to a contract for its use. The Peruvian International Collaborative Biodiversity Group project requires 
the participating indigenous organisations to establish a mechanism for distribution of benefits which will ensure equitable distribution among all Aguaruna and Huambisa peoples, whether or not they are party to the agreement. It is envisaged that a form of trust fund may be established, with representatives of the five river basins inhabited by the Aguarunas and Huambisas on its management board.

Benefits should be administered by indigenous peoples themselves. However, as this is collective property, it will be necessary to ensure that benefits are distributed in a transparent fashion and that the interests of future generations have taken into consideration. The commercial value of traditional knowledge may be exhausted once patents obtained over derivatives of medicinal plants have expired. To this extent custodians have an obligation to ensure that benefits received are used to the advantage of both present and future generations. Investment in development projects, securing land and resource rights, conservation of the environment and strengthening traditional knowledge systems are all avenues by which benefits may be more equitably distributed over generations.

The state has an obligation to promote equitable benefit sharing in accordance with the Convention on Biological Diversity. Indigenous peoples should be advised that if they fail to ensure equitable benefit sharing with other custodians, the state may intervene.

Register of collective property. The regime should provide for a register of indigenous and local community collective property to assist national authorities in determining which communities, or peoples, should be informed and consulted regarding proposed contracts for the use of their collective property, and among whom benefits should be shared. This register would only be declaratory, and would not purport to define which communities have rights. No benefits should accrue to those communities who are registered, beyond the benefit of their identification-to the government and potential users-as interested parties.

\section{A multilateral system to secure prior informed consent}

Any national regime is, by its nature, restricted in its application to the territory within its jurisdictional boundaries. The major commercial markets in which infringements are most likely to occur are generally located in countries other than those from which the knowledge and resources were sourced. The economic and logistical difficulties which indigenous and local communities face in policing the use of their 
collective property limits the effectiveness of any regime which requires custodians to monitor and challenge abuses of rights.

For these reasons, it is proposed that any national regime should be complemented by a market-based mechanism that would reverse the burden of proving the right to use a resource. At present, applicants for patents and other intellectual property rights are not required to demonstrate their right to use the knowledge or resources on which their application is based. Instead, indigenous groups who seek to challenge patents must establish that the applicant does not have that right. It is proposed to reverse this onus, and to place the burden of proving the right to use knowledge or resources on the user, rather than on the country of origin or its local and indigenous communities.

While the idea of using the market as a means to prevent 'biopiracy' is seen by some commentators as the tip of the iceberg through which collective property would eventually be expropriated, an objective consideration leads to a contrary conclusion. In fact the proposal for certificates of origin set out below should not be seen as one which will convert collective property into a negotiable commodity of itself. On the contrary, what is promoted is a mechanism which ensures that, where use of knowledge, innovations and practices has not been the subject of prior informed consent, the opportunities for the user to commercialise any resultant product or process will be severely limited.

Adopting the premise that indigenous and local communities are mainly concerned to prevent the unapproved use of their knowledge, including in some cases any form of commercialisation, the following proposal is directed toward controlling these activities. It is based on an assumption that the desire to access and use knowledge is directly proportional to the potential commercial return to the user. Limiting the possibilities of commercial reward for unapproved use should in turn induce users to seek prior informed consent. It should therefore be seen as an instrument of control rather than an aid to commercialisation.

\section{Incorporating prior informed consent into existing}

\section{intellectual property rights systems}

The ability of a company to make money from a product or process, and therefore their willingness to invest in research and development, is closely linked to the security of intellectual property rights protection. Increasingly, profit potential is also linked to product approval processes 
supervised by national and international standards organisations. The existing regimes for product approval and intellectual property rights have developed over many years. They have been the subject of intense debate, which continues to the present and is likely to continue. The principles underlying these regimes are the subject of divergent views. They are considered by many to be doctrine, by others to represent the evil of capitalistic monopolisation. Given these polarised viewpoints, it seems unlikely that the fundamental tenets of these regimes can be altered, at least in the short term.

The proposal described below seeks to avoid becoming enmeshed in that greater debate; rather than challenging the substantive elements of existing regimes, it focuses on modifying their application procedures. This approach has the additional advantage that, if it is agreed on, it could be implemented by national authorities and standards bodies through administrative rather than legislative means, thereby offering protection in the short rather than the long term. Furthermore, these proposed modifications would still meet the requirements of Article 27 of the Trade-Related Aspects of Intellectual Property Agreement, so no modification of that agreement would be needed to implement it.

Numerous commentators have come to the conclusion that requiring identification of the source of genetic resources and knowledge in patents would help to bring their use to the attention of their custodians. This common view has emerged from a number of individuals whose thinking developed separately in different parts of the world. This convergence of opinion tends to suggest that, not only is a market-based tool a valid option, it is probably the most practical mechanism for monitoring and controlling use of knowledge.

Identification of genetic content and use of knowledge in a patent does not necessarily deal with the issue of prior informed consent. The restrictions which indigenous and local communities will face in policing the use of their resources and the costs of challenging an intellectual property rights grant must also be taken into account. The system must go further and provide for evidence of the right to use the knowledge or resources. This is most effectively achieved if there is a reversal of the burden of proving the right to use knowledge, from the custodian of that knowledge to the user. In this way the intellectual property rights system can employ market tools to regulate use for the market. 


\section{Elements of a certificate of origin scheme}

The following core elements for a certificate of origin scheme are suggested. ${ }^{4}$

Declaration as to the right to use resources. A certificate of origin scheme would require that applicants for patents and other intellectual property rights make a sworn declaration regarding the use of genetic resources and associated knowledge, and provide evidence of their legal right to use such resources for the production of the material for which intellectual property rights protection is sought. Similar requirements could also be included in product approval procedures.

The Food and Drug Administration and the International Standards Organisation, for example, could make it a condition for receipt of applications that evidence of prior informed consent be included. As many products are not subject to patents but are commercially exploited on an industrial scale it is important that mechanisms be used which allow the control of all major commercialisation of genetic resources, collective property and products developed with use of such resources. This requirement would effectively transfer the burden of securing the interests of countries of origin and of indigenous and local communities to the user. This may be likened to the reversal of the burden of proof concerning production of a product over which there exists a patented process, found in many jurisdictions and as included in the TradeRelated Aspects of Intellectual Property Agreement.

Certification of origin. Evidence of the right to use resources could be given either by production of a contract or licence to use the knowledge, or in the form of a certificate issued by the competent authority of the country where the custodians of the knowledge reside. This certificate would include the names of the parties, the tangible and intangible resources being provided and the rights and limitations placed on the user. As in many cases access to knowledge will be linked to access to specific resources, the certificate could cover both knowledge and resources.

Uniform international system. A certificate system common to all nations would help to harmonise procedures and prevent the need to interpret different contract provisions under differing legal regimes. Reid and La Vina (1995:10) argue that harmonised national standards and requirements for biodiversity trade would lessen the hurdles facing users of biodiversity. They suggest that a certification system established in 
conjunction with national standards would help to reduce the illicit trade in genetic resources.

A uniform international system would also protect commercial confidentiality of sensitive contract details not required by the patent authorities. A uniform and recognisable certificate would obviate the need for patent offices to verify the nature of the consent given, a role which they should not be required to perform.

\section{Conclusion}

Although it is desirable that any regime to protect indigenous and local community interests be drafted by indigenous peoples, some form of protection is needed in the short term. A blend of national and international measures will be necessary to ensure comprehensive and effective protection. By recognising rights at the national level, and impeding use of knowledge for commercial purposes through a multilateral agreement requiring countries to modify intellectual property rights and product approval application procedures, an interim mechanism can be established which would effectively prevent unapproved commercial use of knowledge.

The Conference of the Parties for the Convention on Biological Diversity should be asked to establish an ad hoc experts group on collective property, with a mandate to consider possibilities for adoption of an international accord on indigenous and local community knowledge rights. This group must include representatives of indigenous peoples and should commence a global participative process to determine the format that such a regime should take. 


\section{Notes}

1 The International Collaborative Biodiversity Group Peru project is one of five projects worldwide financed by the US National Institute of Health, National Cancer Institute and the National Science Foundation. For further reading on the International Collaborative Biodiversity Group Peru Project and the agreements associated with it see Tobin (1997b).

2 Article 24 of the new Peruvian Law on the Conservation and Sustainable use of Biological Resources, Ley No. 26839, adopted on 27 July 1997, recognises that the knowledge, innovations and practices of indigenous peoples are their cultural patrimony and that they hold rights over it and are entitled to decide over its use.

3 It is possible that a specific community or group of communities have a body of knowledge which is not shared with other indigenous peoples, and that all the custodians agree to give an exclusive right to a particular user. There may be good commercial reasons for doing so, as well as reasons relating to maintenance of control over the knowledge. In such an instance exclusivity may be appropriate in so far as the rights are granted under licence, may be revoked for noncompliance and do not preclude future generations from utilising the knowledge to their benefit.

4 For a comprehensive bibliography and further reading on certificates of origin see Tobin (1997a). 